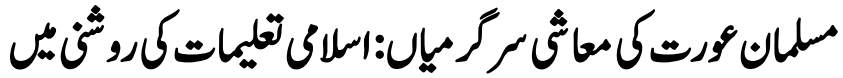

\section{Muslim Woman in Economic Activities: In the Light of the Teachings of Islam}

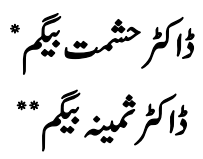

\section{Abstract}

Women of today are engaged in almost all field of life including army, politics, sports, culture, education, engineering, space and agriculture etc. Education enable women expand their scope of activities for contribution to their nation and state which is relevant to the teachings of Islam.

Islam allows women outside homes for work, education \& business besides giving equal economic rights as par with men. Even Quran binds women for promoting virtue and forbidding sins. Quran at many Places mentions woman is spending for sadaqa \& zakat.

In the life of holy prophet Muhammad (P.B.U.H), women had under taken various professions like agriculture and animal husbandry, trade and small seal industrial products.

Muslim women are allowed to undertake any profession but within certain limits. In this article the role of a Muslim Women will be discussed in economic activities along with their permitted and prohibited fields.

Keywords: Women, Economic rights, Quran, Islam

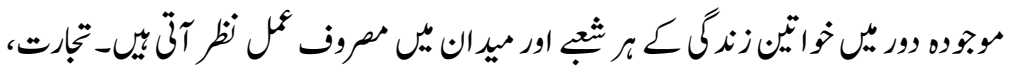

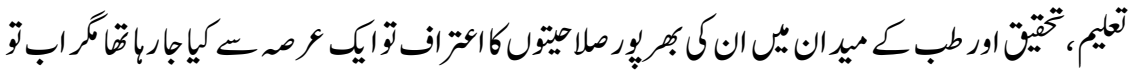

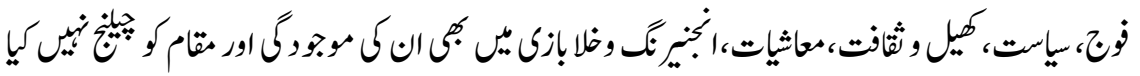

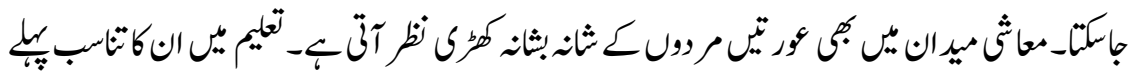

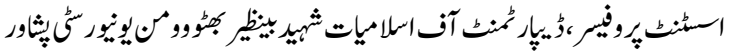

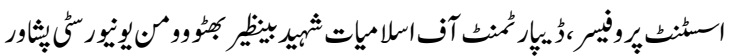




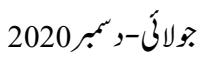

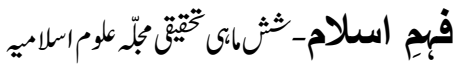

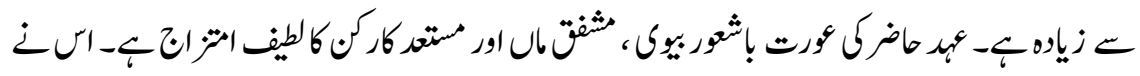

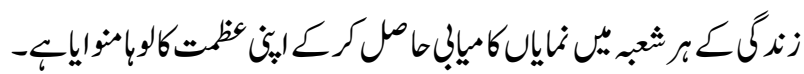

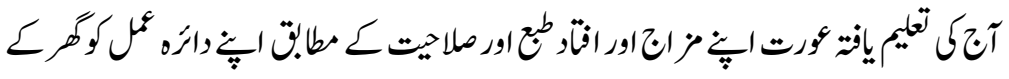

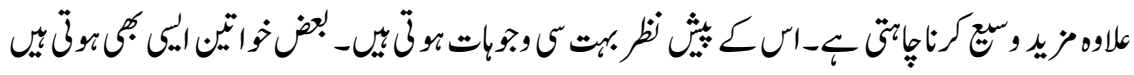

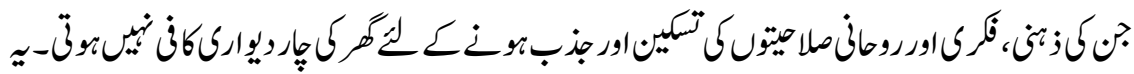

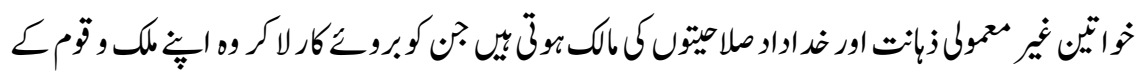

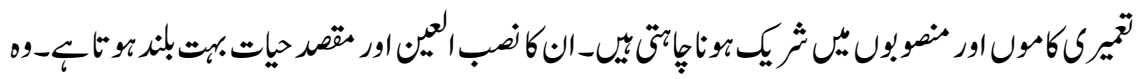

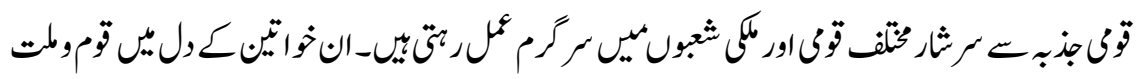

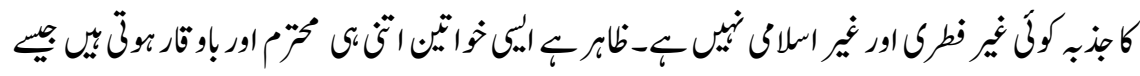

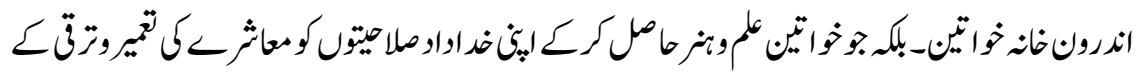

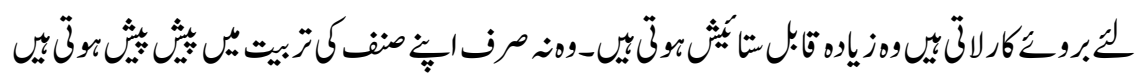

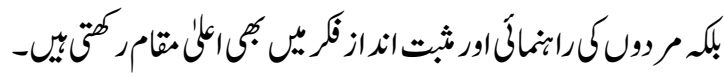

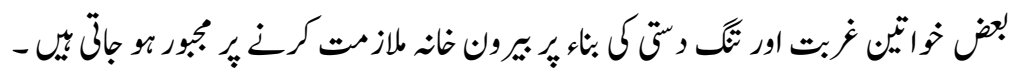

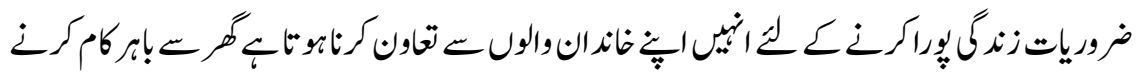

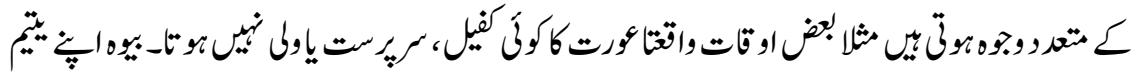

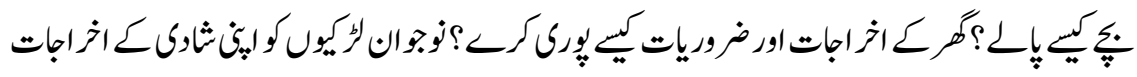

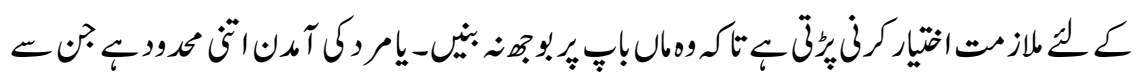

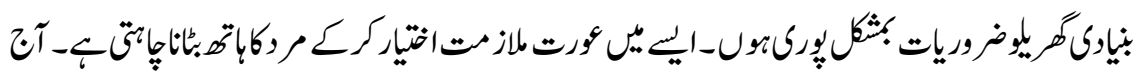

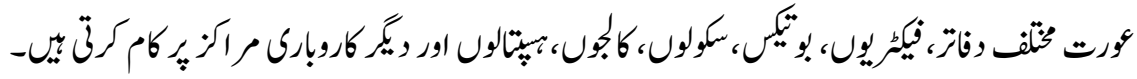

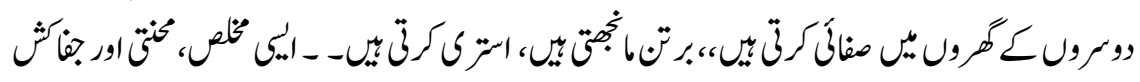

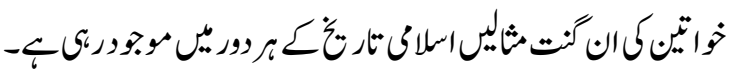

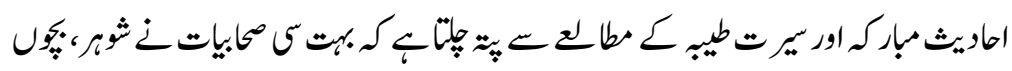

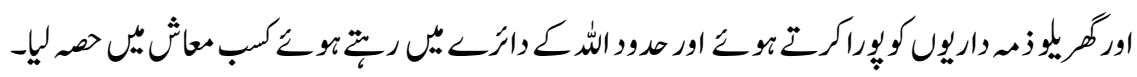

134 


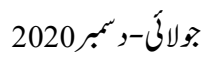

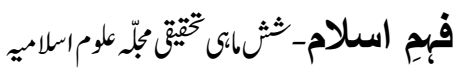

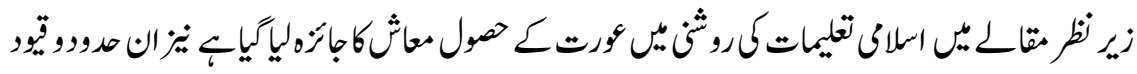

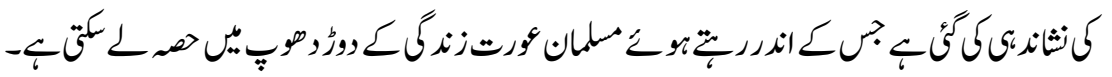

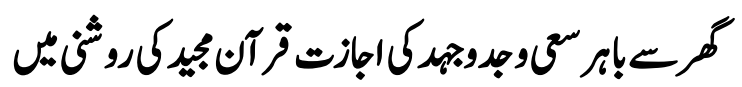

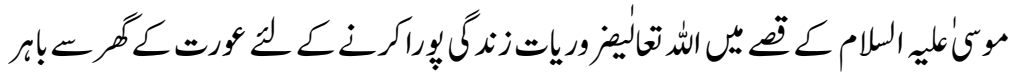

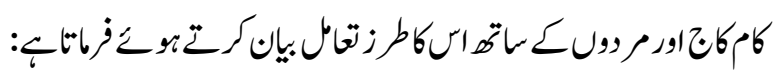

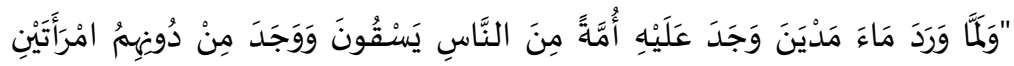

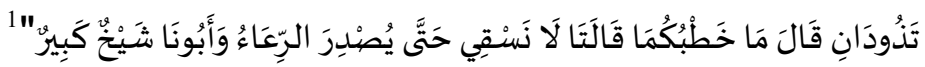

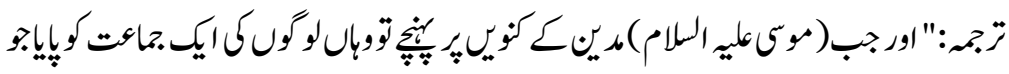

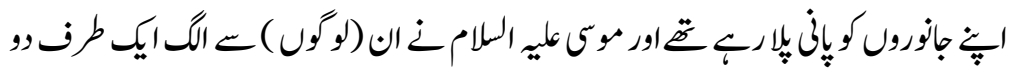

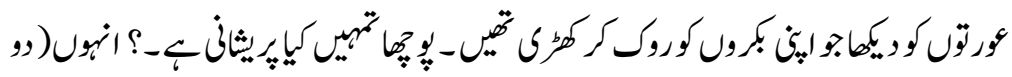

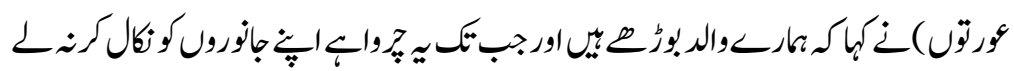

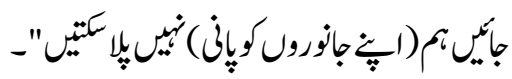

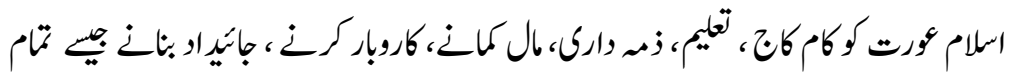

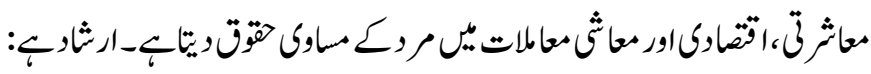

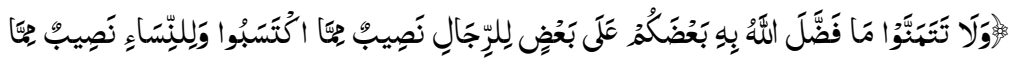

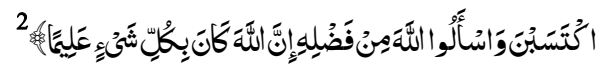

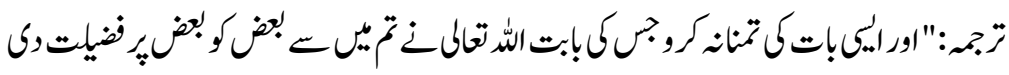

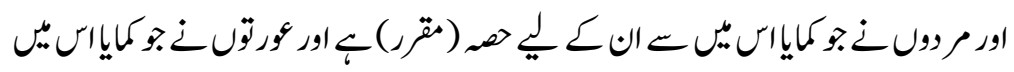

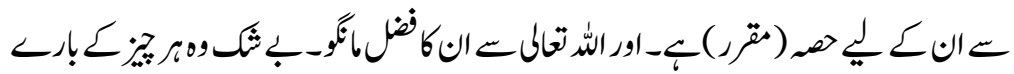

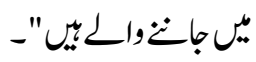

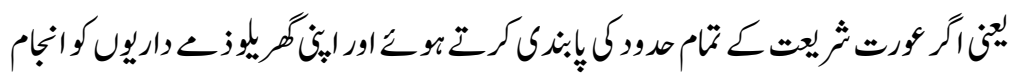

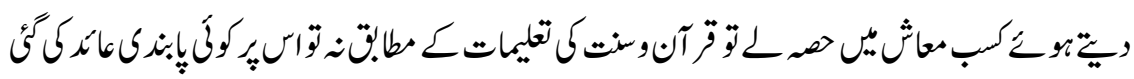

135 


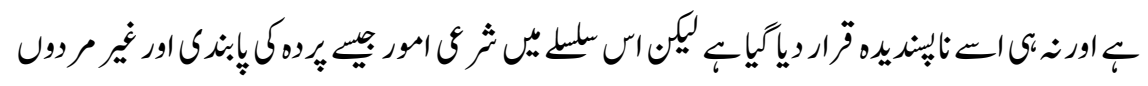

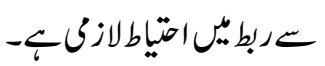

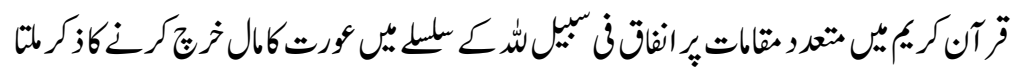

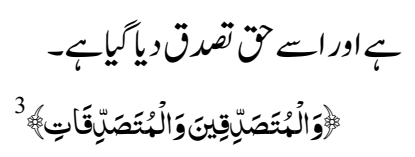

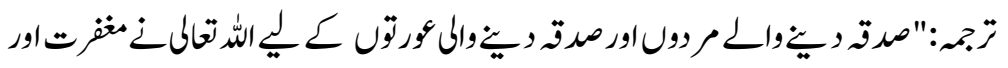

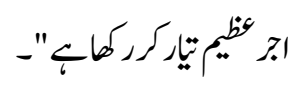

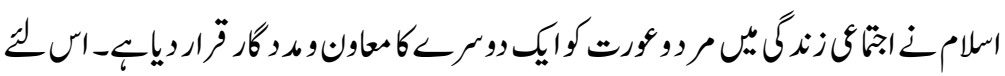

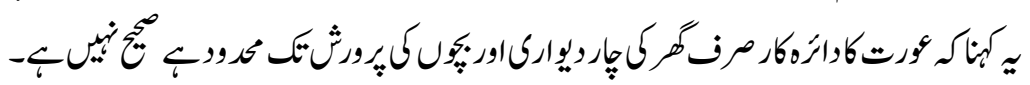

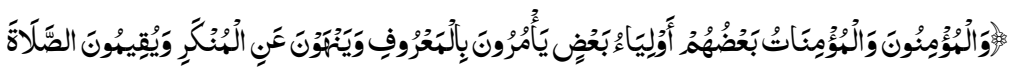

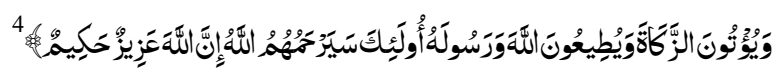

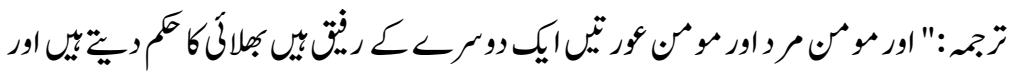

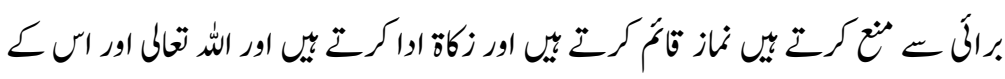

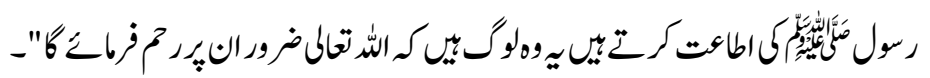
"عن عائشة رضي الله عنها قالت خرجت سودة بعد ما ضرب الحجاب لحاجتها

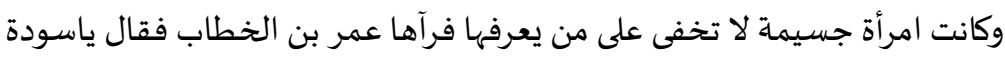
أما والله ما تخفين علينا فانظري كيف تخرجين . قالت فانكفأت راجعة ورسول الله

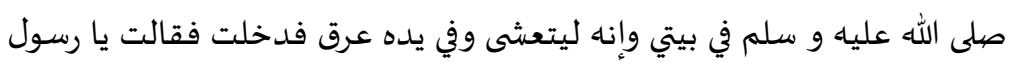
الله إني خرجت لبعض حاجتي فقال لي عمر كذا وكذا قالت فأوحى الله إليه ثم رفع

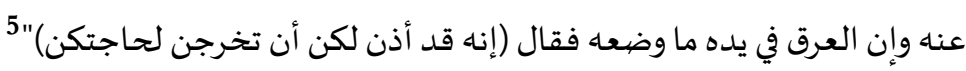

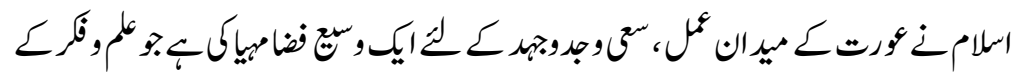
ميان 


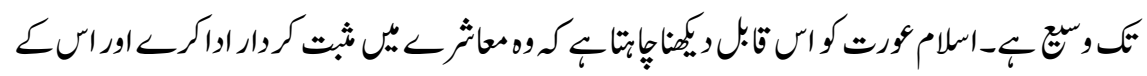

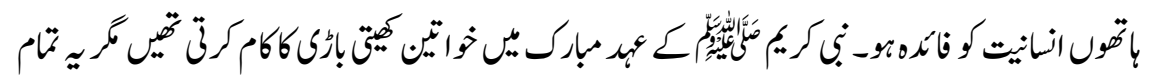

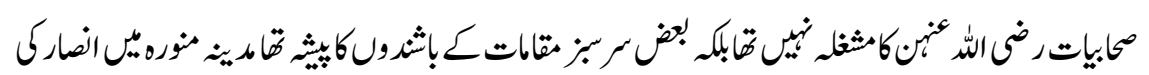

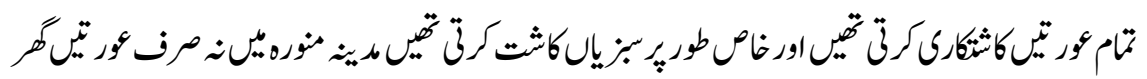

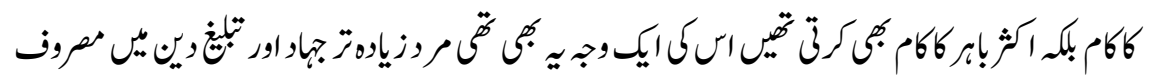

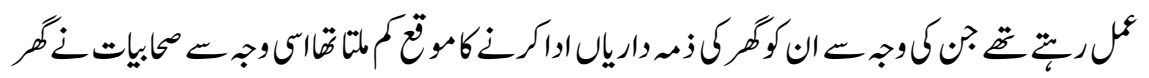

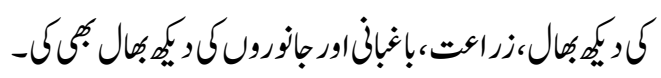

\section{6}

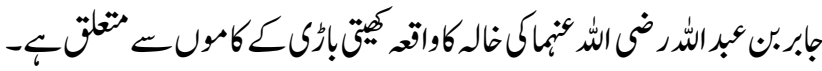

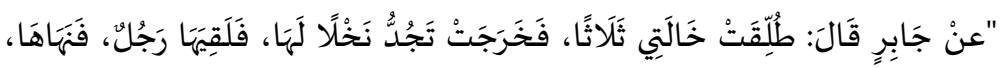

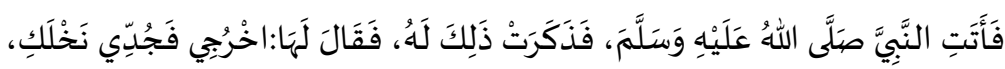

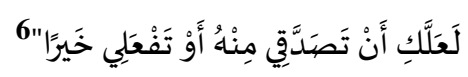

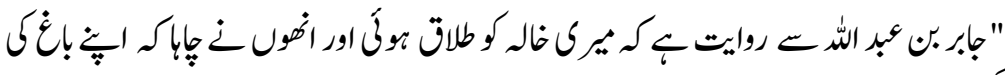

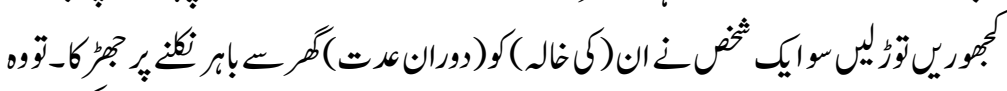

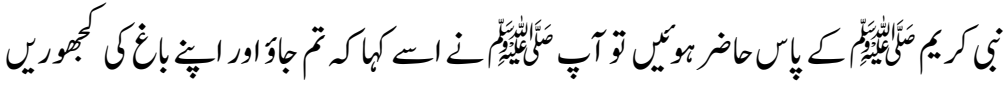

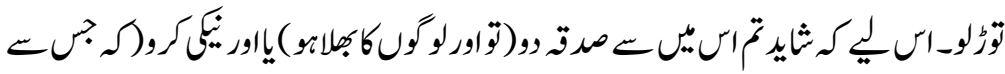

")

"عن سهل قال : كانت فينا امرأة تجعل على أربعاء في مزرعة لها سلقا فكانت إذا كان

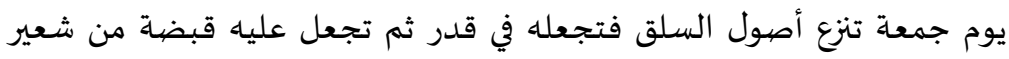
تطحتها فتكون أصول السلق عرقه وكنا ننصرف من صلاة الجمعة فنسلم علهيه

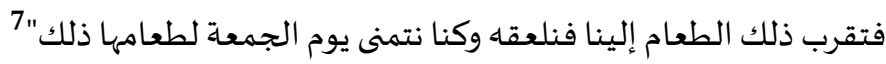

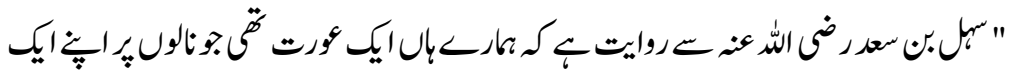

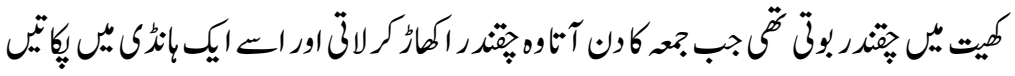




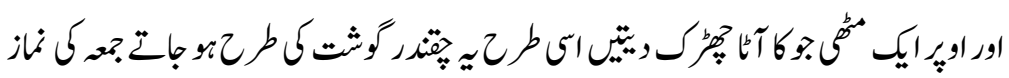

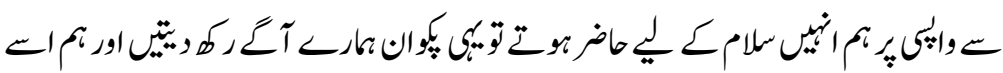

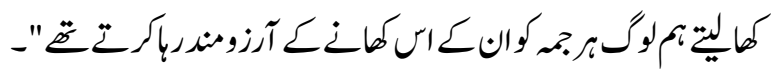

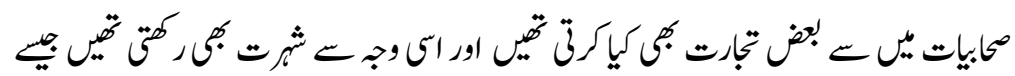

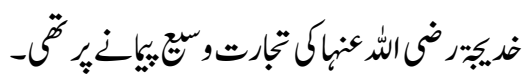

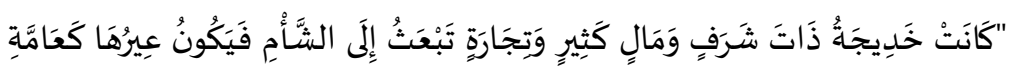

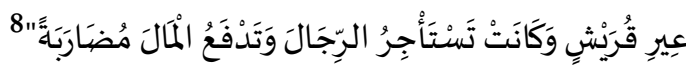

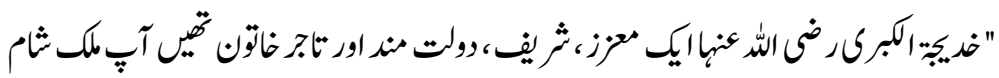

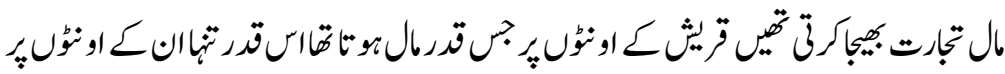

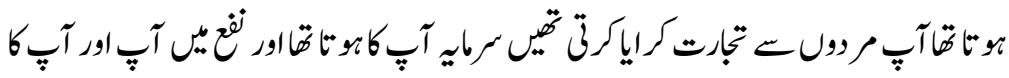

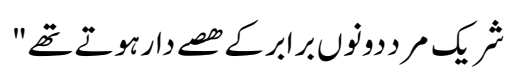

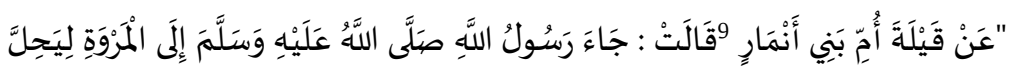

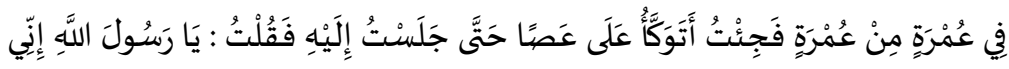

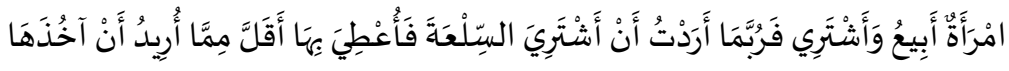

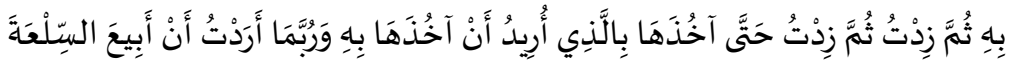

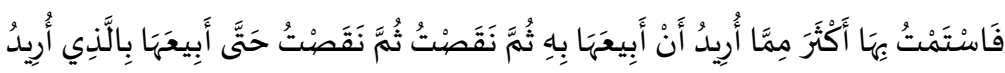

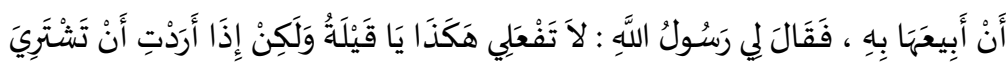

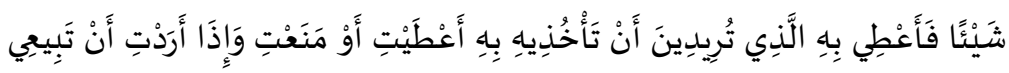

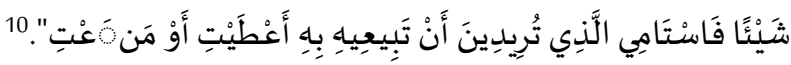

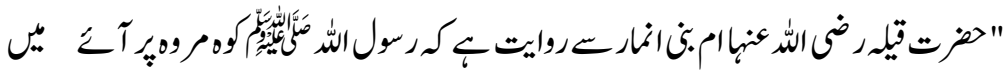

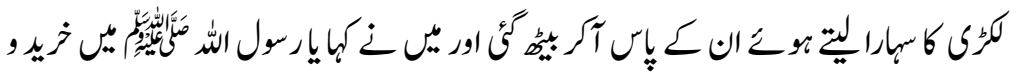

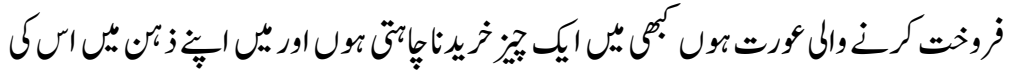




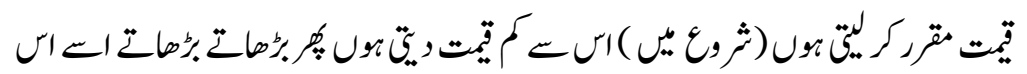

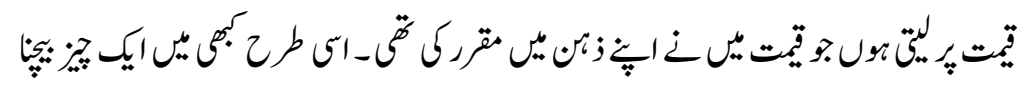

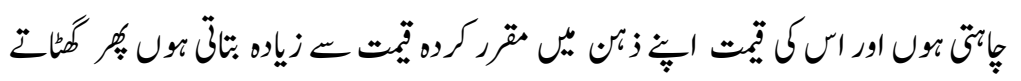

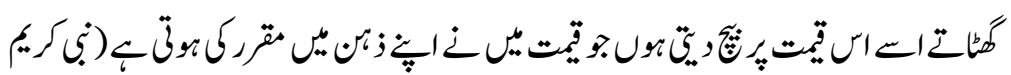

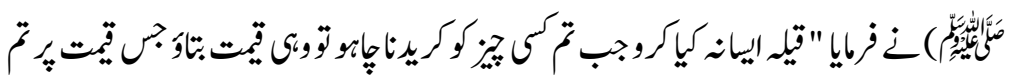

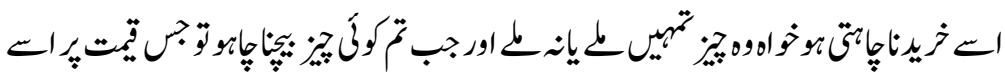

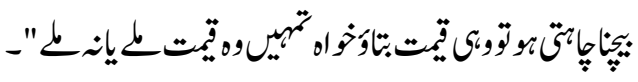

\section{ساكَكرّماكَاور صنعتوحزت}

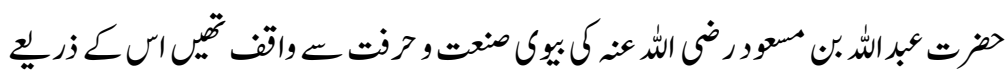

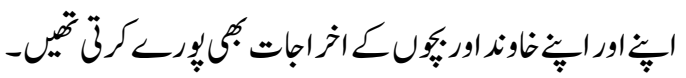

"عن رائطة امرأة عبد الله بن مسعود ـ............. فأتت رسول الله صهلى الله عليه و سلم فقالت يا رسول الله إني امرأة ذات صنعة أبيع منها وليس لي ولا لولدي ولا

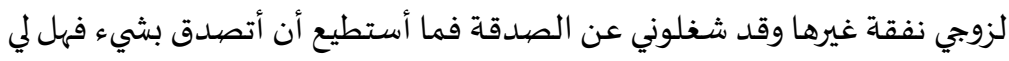
من أجر فيما أنفقت قال فقال لها رسول الله صلى الله عليه و سلم : أنفقي عليهم

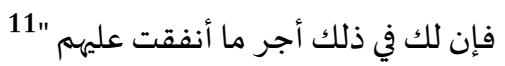

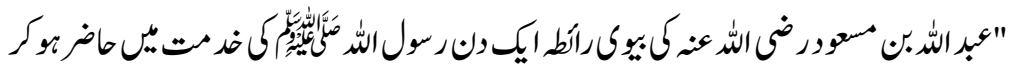

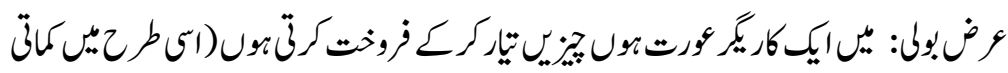

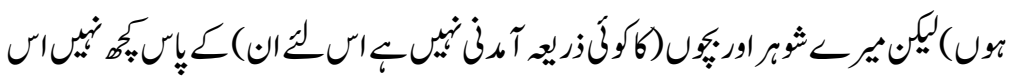

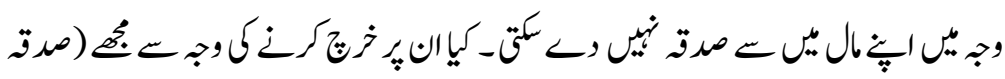

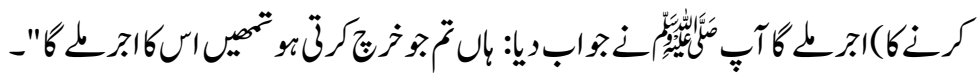

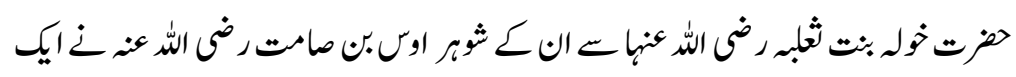

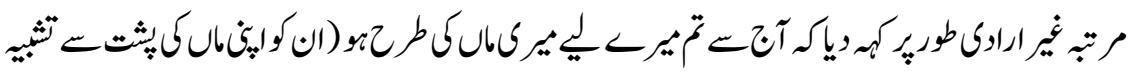

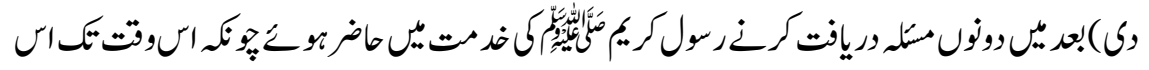




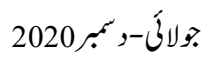

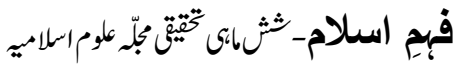

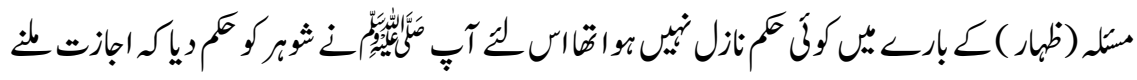

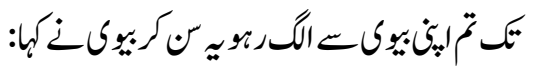

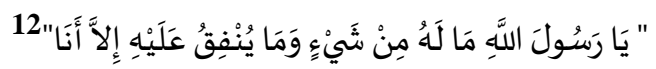

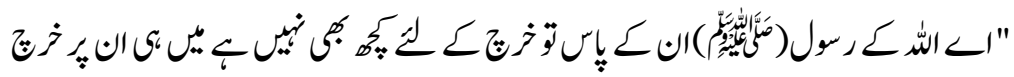

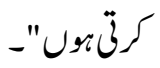

"عن ربيع بنت معوذ ، قالت : كان عُمَر بن الخطاب قد استعمل عبد الله بن أبي

ربيعة على اليمن ، فكان يبعث إلى أمه أسماء بنت مخربة وهي أم أبي جهل بعطر من

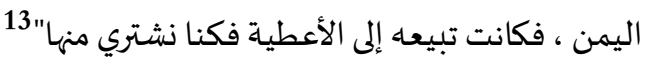

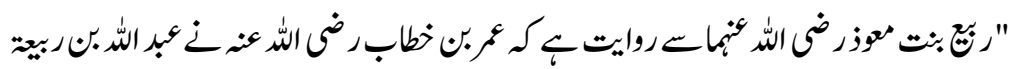

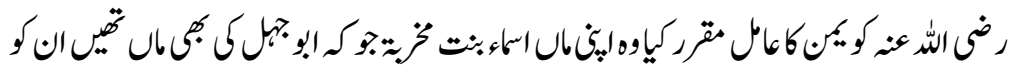

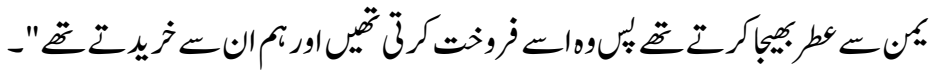

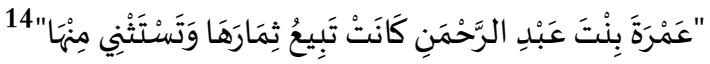

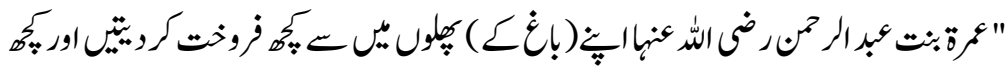

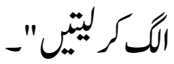

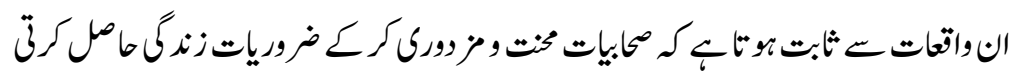

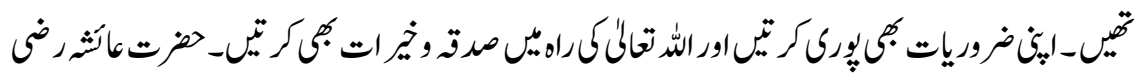

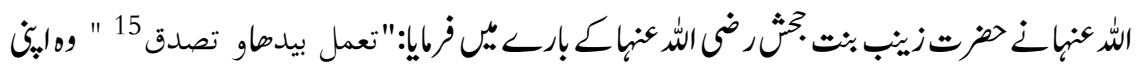

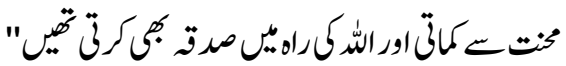

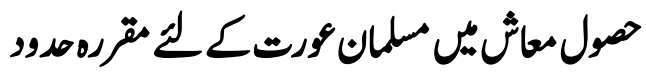

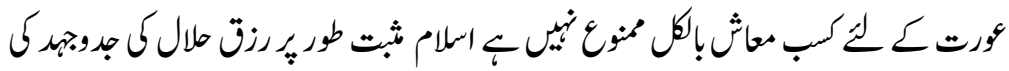

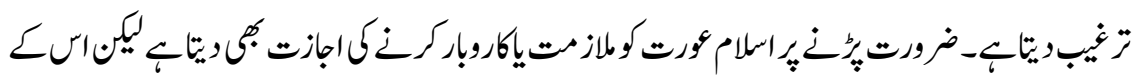

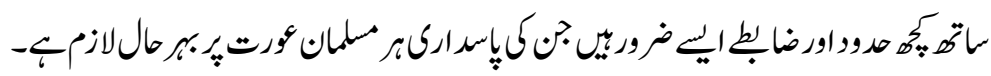

140 


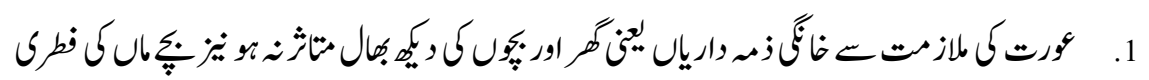

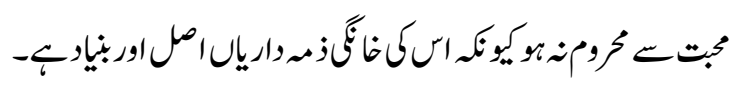

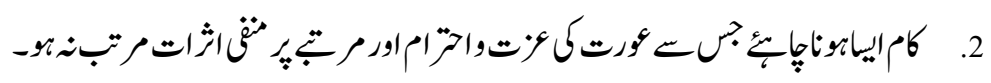

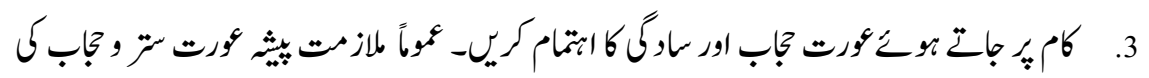

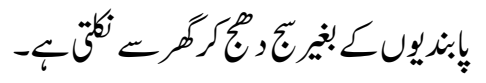

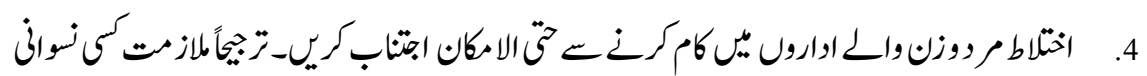

$$
\text { اوارحبيّن }
$$

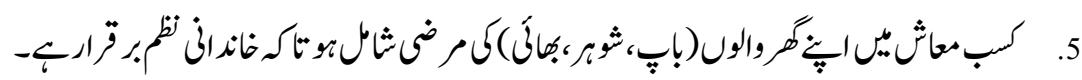

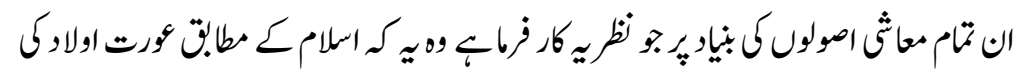

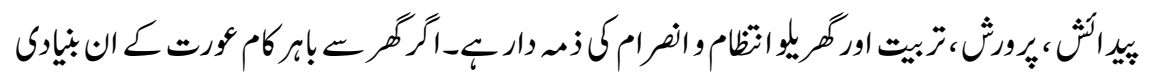

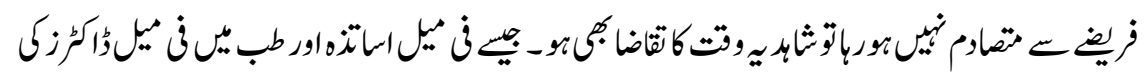

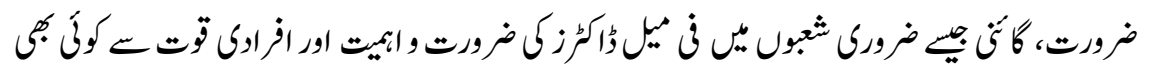

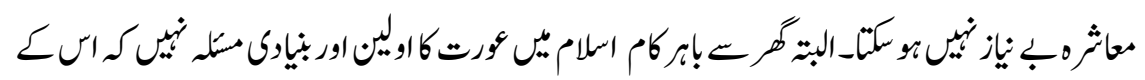

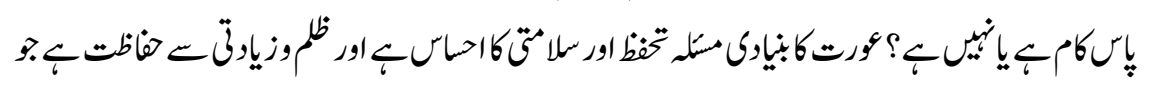

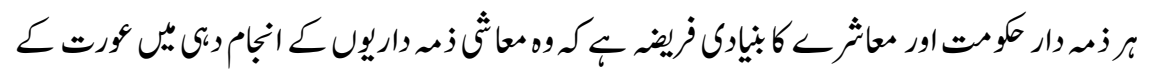

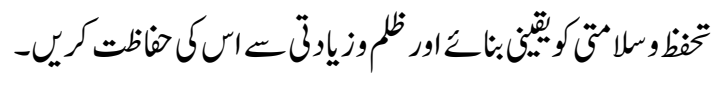

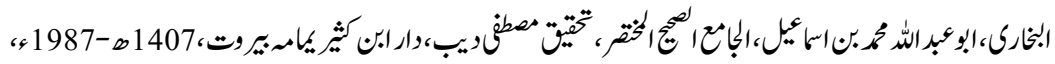

$$
\begin{aligned}
& \text { الق آن الكريكه بوره وصن:23 } \\
& \text { التر آن الكريك، بورة الناء:32 }
\end{aligned}
$$

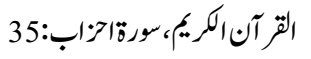

$$
\begin{aligned}
& 4 \text { الت آن الكريز:ورة|التوب: } 71
\end{aligned}
$$

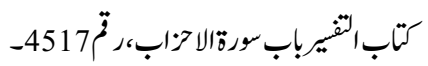

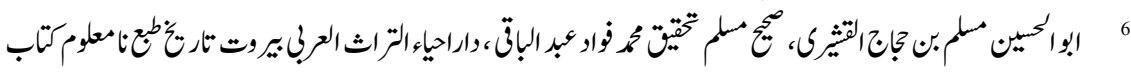




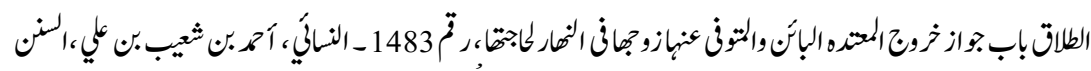

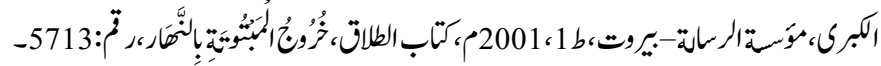

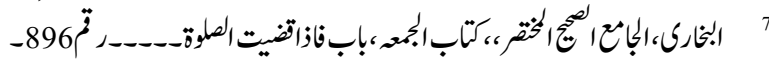

8

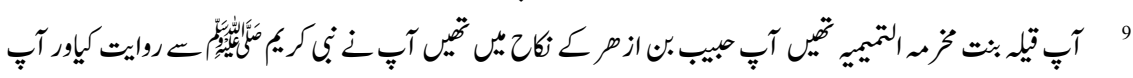

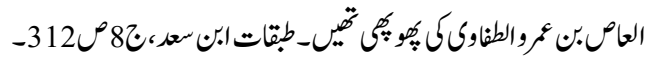

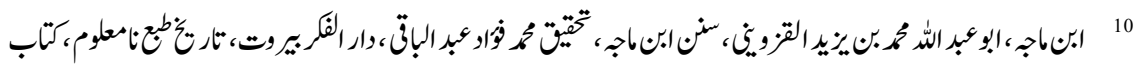

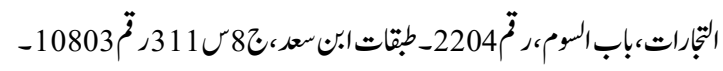

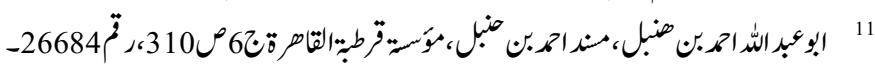
12 13

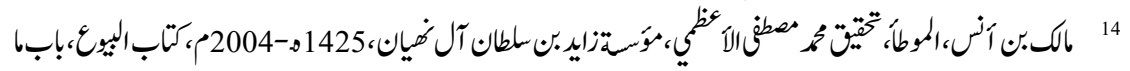

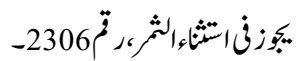

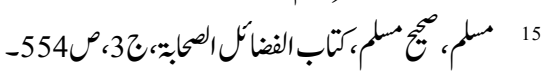

